\title{
REVIEW
}

\section{The effects of policy actions to improve population dietary patterns and prevent diet-related non-communicable diseases: scoping review}

\author{
L Hyseni, M Atkinson, H Bromley, L Orton, F Lloyd-Williams, R McGill and S Capewell
}

\begin{abstract}
Poor diet generates a bigger non-communicable disease (NCD) burden than tobacco, alcohol and physical inactivity combined. We reviewed the potential effectiveness of policy actions to improve healthy food consumption and thus prevent NCDs. This scoping review focused on systematic and non-systematic reviews and categorised data using a seven-part framework: price, promotion, provision, composition, labelling, supply chain, trade/investment and multi-component interventions. We screened 1805 candidate publications and included 58 systematic and non-systematic reviews. Multi-component and price interventions appeared consistently powerful in improving healthy eating. Reformulation to reduce industrial trans fat intake also seemed very effective. Evidence on food supply chain, trade and investment studies was limited and merits further research. Food labelling and restrictions on provision or marketing of unhealthy foods were generally less effective with uncertain sustainability. Increasingly strong evidence is highlighting potentially powerful policies to improve diet and thus prevent NCDs, notably multi-component interventions, taxes, subsidies, elimination and perhaps trade agreements. The implications for policy makers are becoming clearer.
\end{abstract}

European Journal of Clinical Nutrition (2017) 71, 694-711; doi:10.1038/ejcn.2016.234; published online 30 November 2016

\section{INTRODUCTION}

Non-communicable diseases (NCDs) now exceed 34 million deaths annually (65\% of global deaths). NCDs, particularly cardiovascular diseases, common cancers, respiratory diseases, diabetes and dementia, are a common cause of disability. ${ }^{1}$

Four major risk factors generate the majority of NCDs. Of these, poor diet makes the biggest contribution, larger than tobacco, alcohol and physical inactivity combined. ${ }^{2}$ Globally, increased consumption of processed food containing excess amounts of sugar, salt, saturated and trans fats are compounded by low intakes of healthy foods like fruit and vegetables, whole grains, nuts, pulses and seafood.

Hence a key policy question is: how can diets be improved to prevent NCDs? Two options are often discussed: 'downstream' behavioural interventions focusing on individuals or, the focus of this review, 'upstream' policy interventions that aim to promote healthier environments. ${ }^{3}$ Worldwide, many different 'upstream' policy options have been proposed to promote healthier eating and prevent diet-related NCDs. These include targeting price, promotion, provision, composition, labelling, supply chain, trade and investment, or a combination thereof. ${ }^{4}$ However, these options are broad and potentially confusing, with continuing uncertainties about which interventions are most effective. To inform their decisions, policy makers need clear evidence on the potential population benefits (as well as the ease and cost of implementation).

This scoping review, therefore, collates the current evidence on policy interventions to promote healthier dietary consumption.

\section{METHODS}

\section{Search strategy}

We first identified exemplar studies of dietary interventions, which were used to define and refine search terms. This process identified interventions targeting price, promotion, provision, composition, labelling, supply chain, trade and investment. ${ }^{4}$ This search strategy was piloted for price interventions to determine appropriate databases for identifying all relevant studies and was adapted for the remaining interventions.

The search strategy consisted of a combination of two sets of keywords. The first one focused on dietary components such as salt, fruit, vegetables, fat, trans fat, sugar, diet or equivalents of these terms. The second search string focused on policy interventions including taxes, subsidies, reformulation, elimination, labelling, campaigns, marketing, advertisement, workplace, schools, community, food system, food supply chain, food trade, food investment, legislation, regulation or equivalents of these terms.

A total of six databases were searched: MEDLINE; Science Citation Index, SCOPUS, Cochrane Database of Systematic Reviews, The Campbell Collaboration Library of Systematic Reviews and the CRD Wider Public Health database. These were identified during the pilot searches as the most appropriate databases to generate relevant papers on this specific topic. Reference lists of included papers were also scanned for potential eligible reviews and systematic reviews (SR).

Selection of studies and inclusion criteria

Systematic and non-SRs addressing policy interventions to improve healthy eating and to prevent NCDs, with a quantitative 
outcome, dating from January 2004 onwards were included. A PICOS approach (participants, interventions, comparators, outcomes and study design) was used to assess the retrieved studies (Table 1). Only reviews in English were considered.

One researcher (LH) conducted the searches and removed duplicates. All remaining titles and abstracts were screened independently by two researchers (LH and MA), based on the inclusion/exclusion criteria (Table 1). All papers deemed potentially eligible were retrieved in full-text form and again screened independently by two researchers. Discrepancies on whether to include or exclude reviews were resolved by consensus or by seeking the opinion of a senior team member (SC).

Data extraction

Both empirical studies (presenting primary data) and modelling studies (using secondary data to project health outcomes) were included. However, the results were analysed and discussed separately, recognising their different natures.

Data extraction was done by one researcher using pre-designed and pre-piloted forms (Table 2 and Supplementary file 1). Extracted data was independently verified by another researcher to ensure accuracy and completeness. Owing to logistical and time constraints, it was not possible to contact study authors regarding any unclear, missing or additional data.

\section{Data categorisation}

Evidence from the reviews was categorised using a seven-part framework, which was developed and refined from the '4Ps' marketing framework: ${ }^{4}$ price, place, promotion and product. In social marketing these 4Ps are key in planning and implementing strategies and this translates well to a policy context. In the social marketing mix, product stands for the desired behaviour and what people will gain when they perform the behaviour, whereas in the policy context this refers to the actual product (for example, foods). Price refers to the cost exchanged for the promised benefits and place refers to the location where the goods are distributed. Finally, promotion refers to a persuasive communication strategy to influence change and can involve multiple channels and target groups. After extensive piloting the following categories were used:

- Food price-policies influencing prices through taxes, subsidies or economic incentives;

- Food promotion-advertising/marketing; particularly on children; media campaigns and health education;

- Food provision-in specific settings: schools, communities or workplaces;

- Food composition-reformulation or elimination;

- Food labelling-nutrition labelling, calorie labelling in stores/ restaurants;

- Food supply chain, trade and investment-including legislation or regulation affecting production policies or supply-chain logistics;

- Multi-component interventions (including at least two of the categories described above).

\section{Data analysis}

We used a narrative synthesis to summarise the evidence of policy interventions to promote healthy eating patterns. ${ }^{55}$ First, the data identified and included in this review were extracted in tables and grouped based on their type of intervention. The different types of interventions included are discussed under data categorisation

Table 1. Inclusion/exclusion criteria

Participants

$\begin{array}{lll}\text { Include } & \text { Exclude }\end{array}$

Systematic and non-systematic reviews reporting a quantitative

assessment of the effects (intended or unintended) of actions to improve

All studies considered ineligible

healthy eating

Interventions

Systematic and non-systematic reviews evaluating the effects of dietary actions that are: implemented by government policy; applied experimentally; or adopted in specific settings

\section{Comparators}

Systematic and non-systematic reviews were included in the review where actions to improve healthy diet and actions promoting NCD prevention were evaluated or compared

Outcomes

The primary outcome of interest was dietary intake (consumption) Secondary outcomes included changes in clinical/physiological indicators related to NCDs and behaviours associated with a healthy diet

Reviews were excluded if no comparisons of different actions to improve healthy diet or preventing NCDs were presented

Process evaluations reporting on implementation of interventions or policies without any quantitative outcome data; data only on costs, feasibility or acceptability without an assessment of primary effects (intake); studies on individuals as opposed to groups or whole populations; under nutrition; micro-nutrient deficiencies, micro-nutrient fortification; supplements

\section{Study design}

Systematic and non-systematic reviews that consisted of modelling studies, secondary analyses, randomised controlled trials, natural experiments, before vs after interventions and modelling studies were included. Furthermore, this review included studies for all age groups and all populations from high-, middle- and low-income countries
Commentary/opinion articles; purely qualitative evaluations with no quantitative assessment; data/statistics from monitoring and surveillance that were not directly linked to a policy intervention; reviews/studies of under nutrition

Abbreviation: NCD, non-communicable disease. 


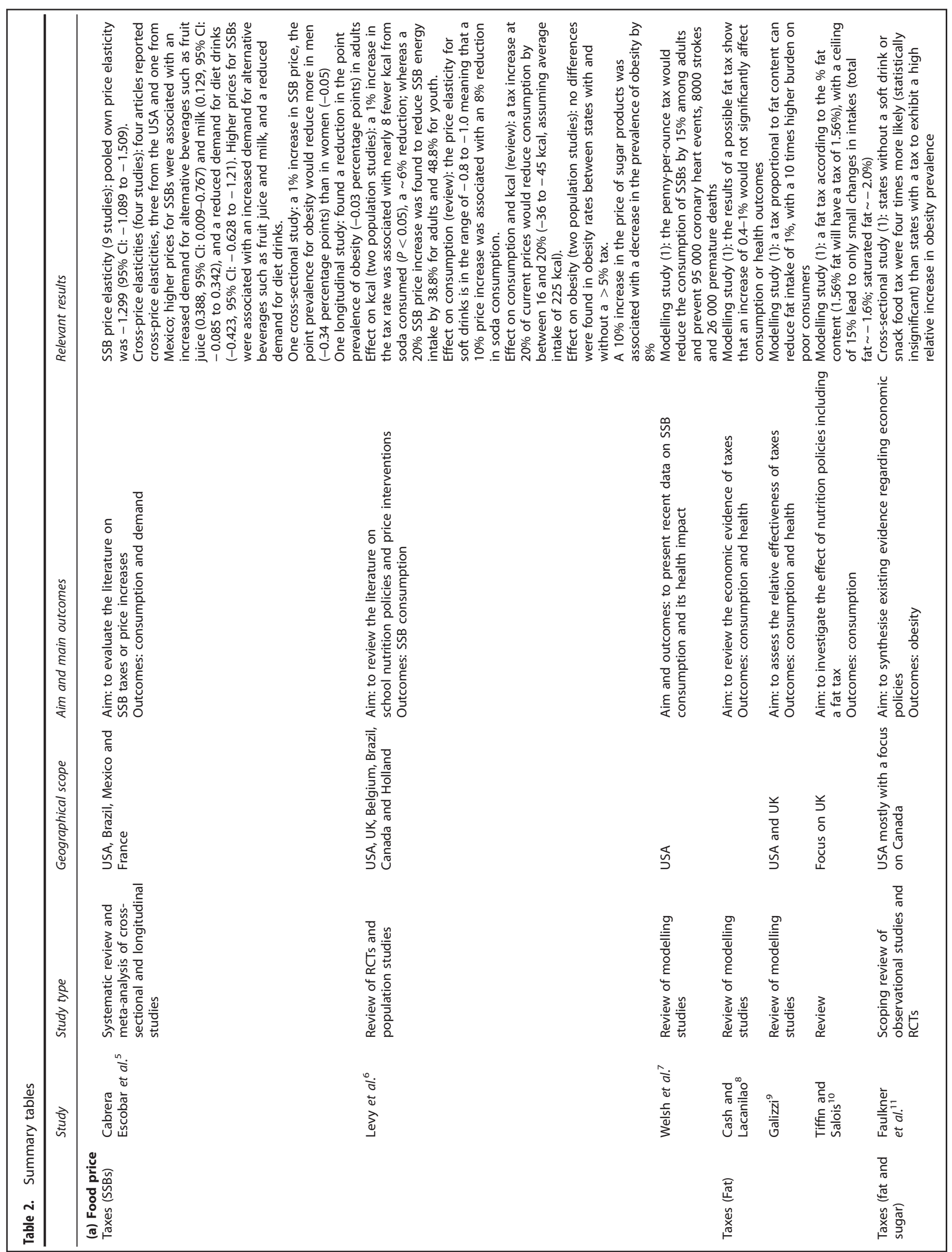




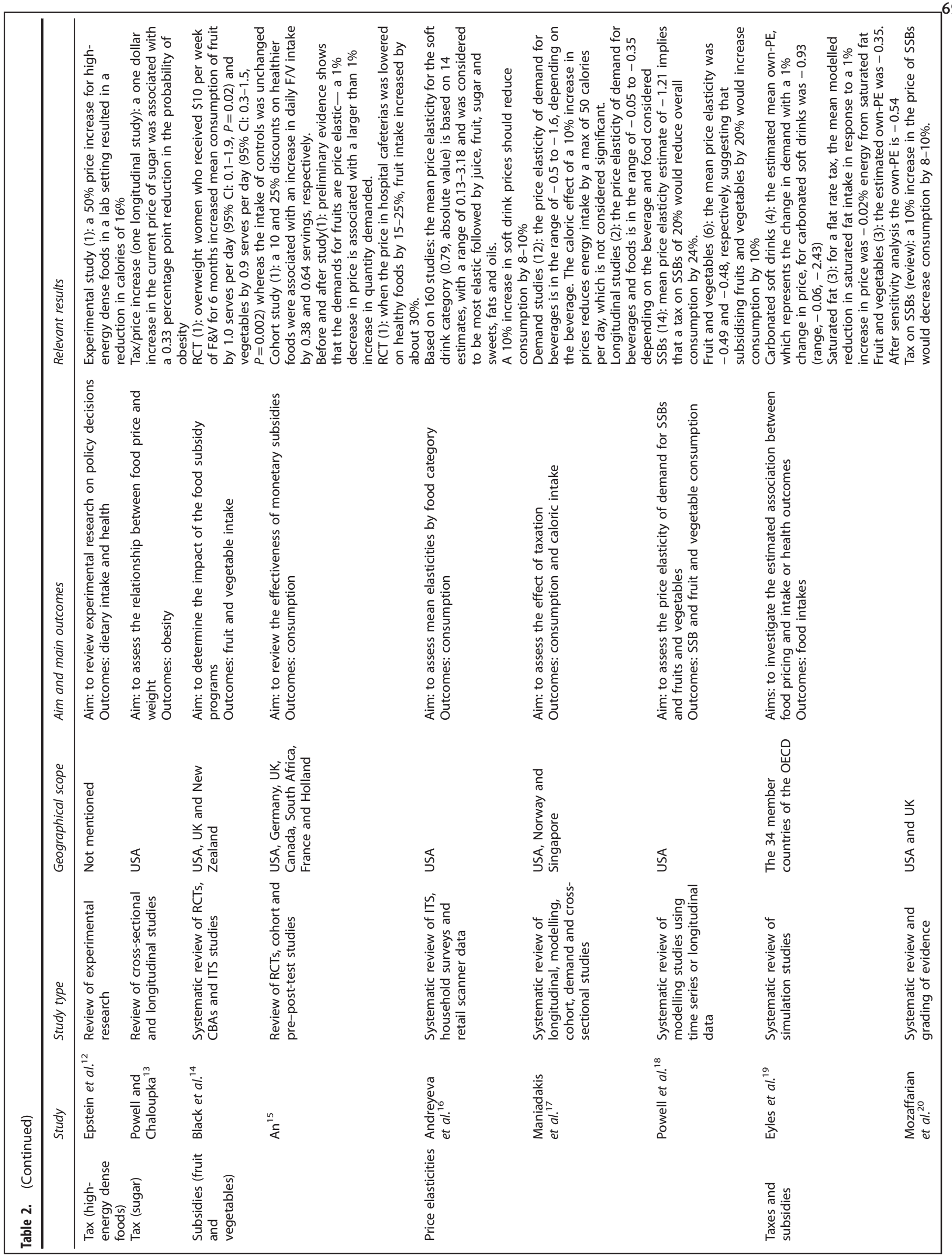




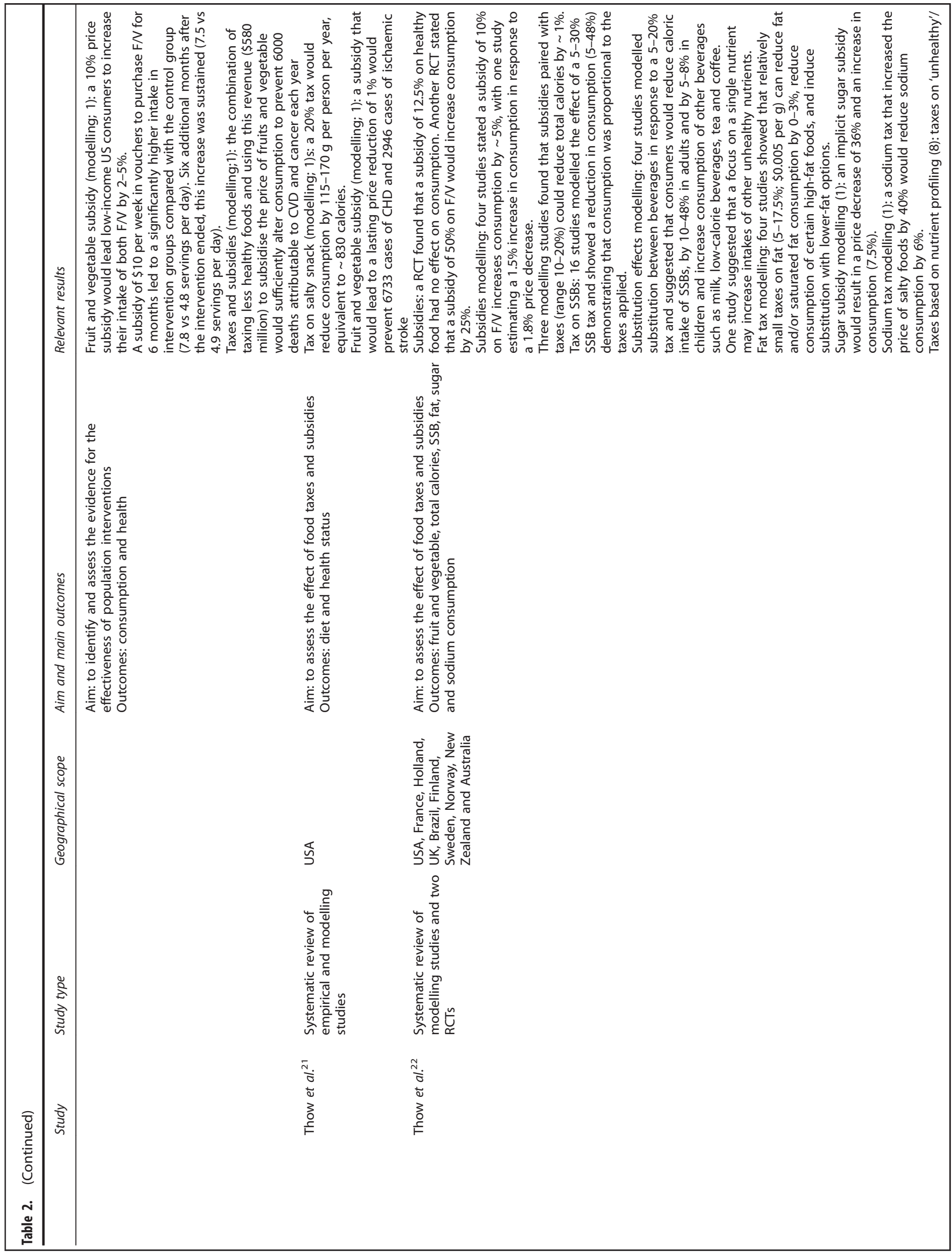




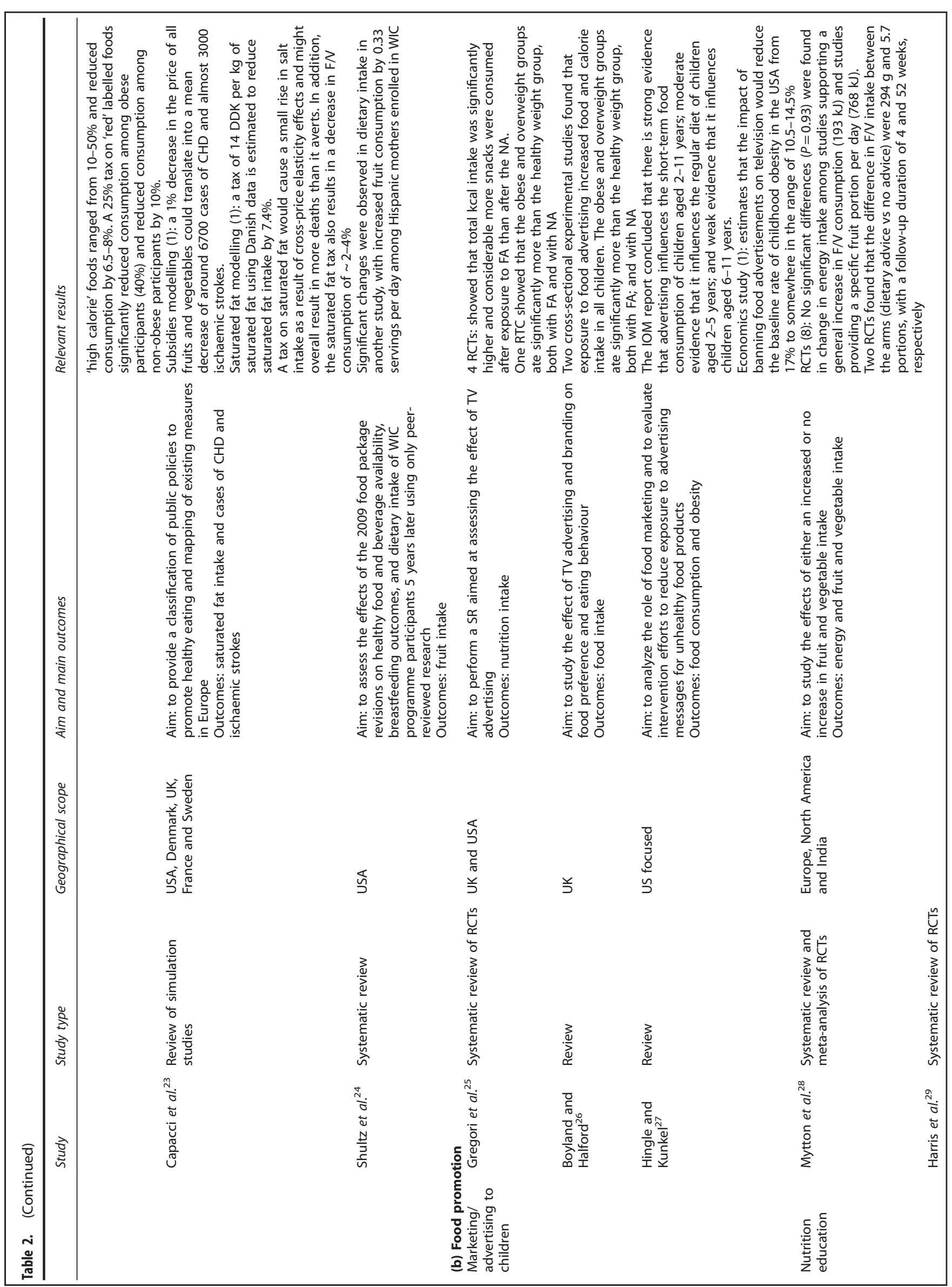




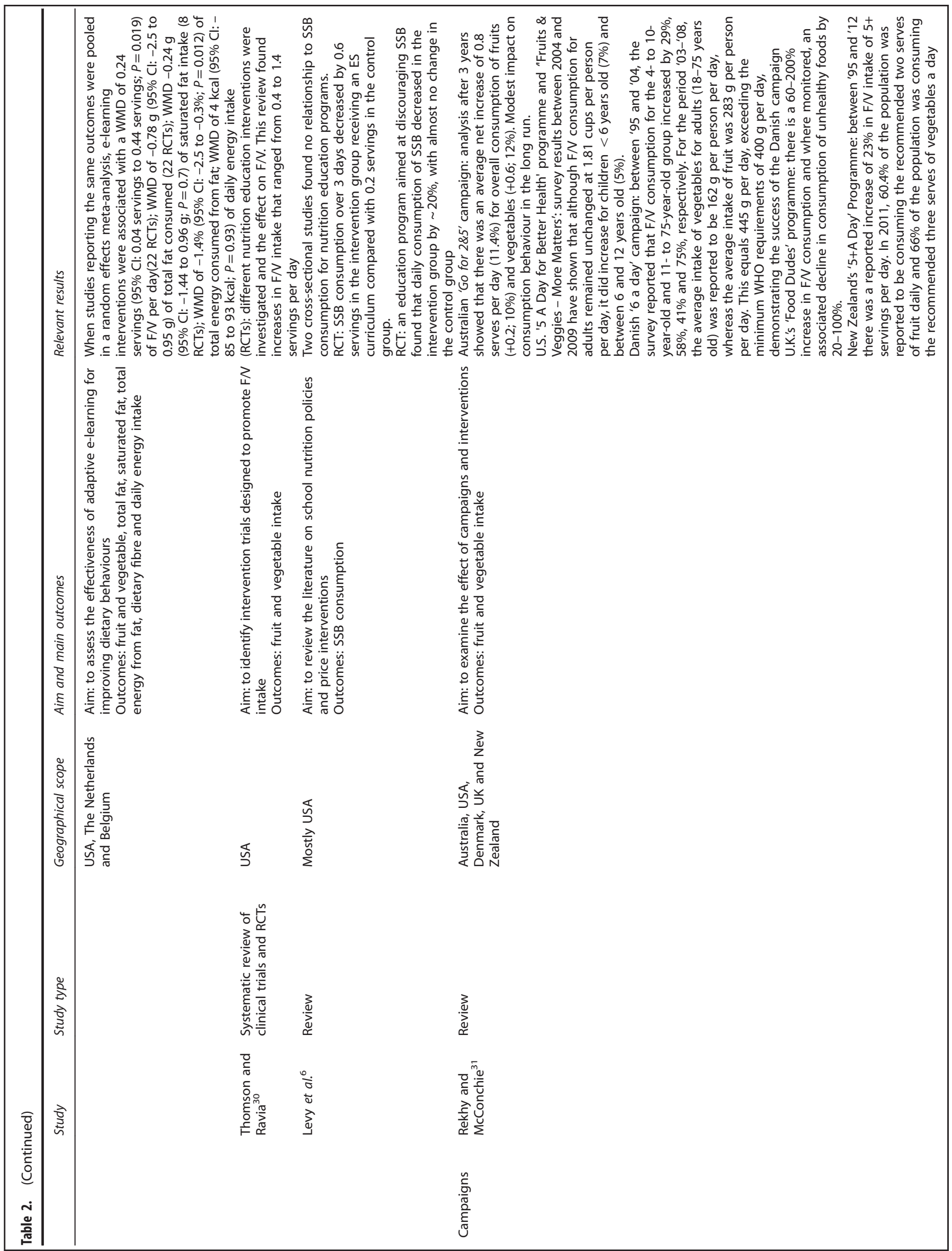




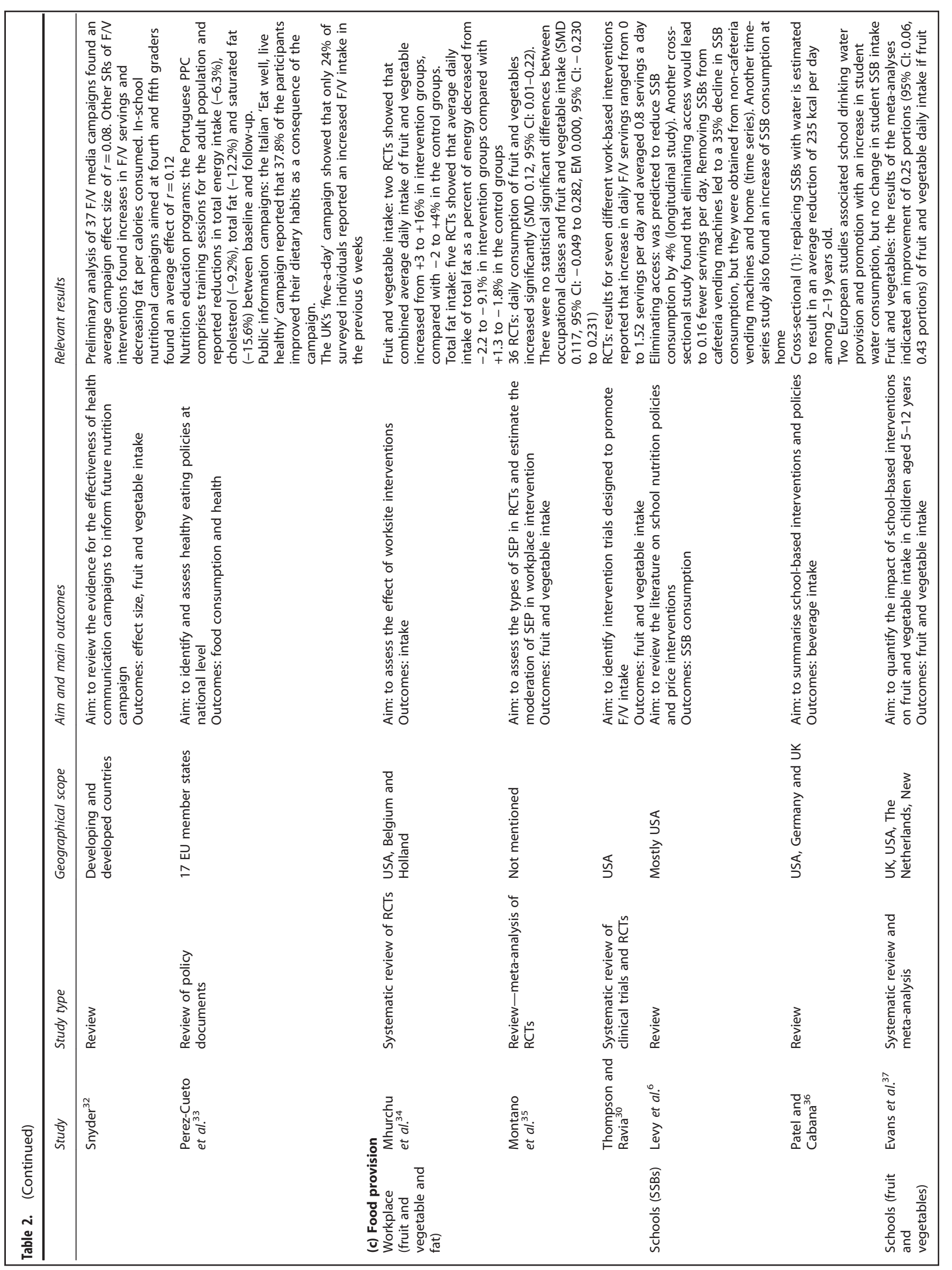




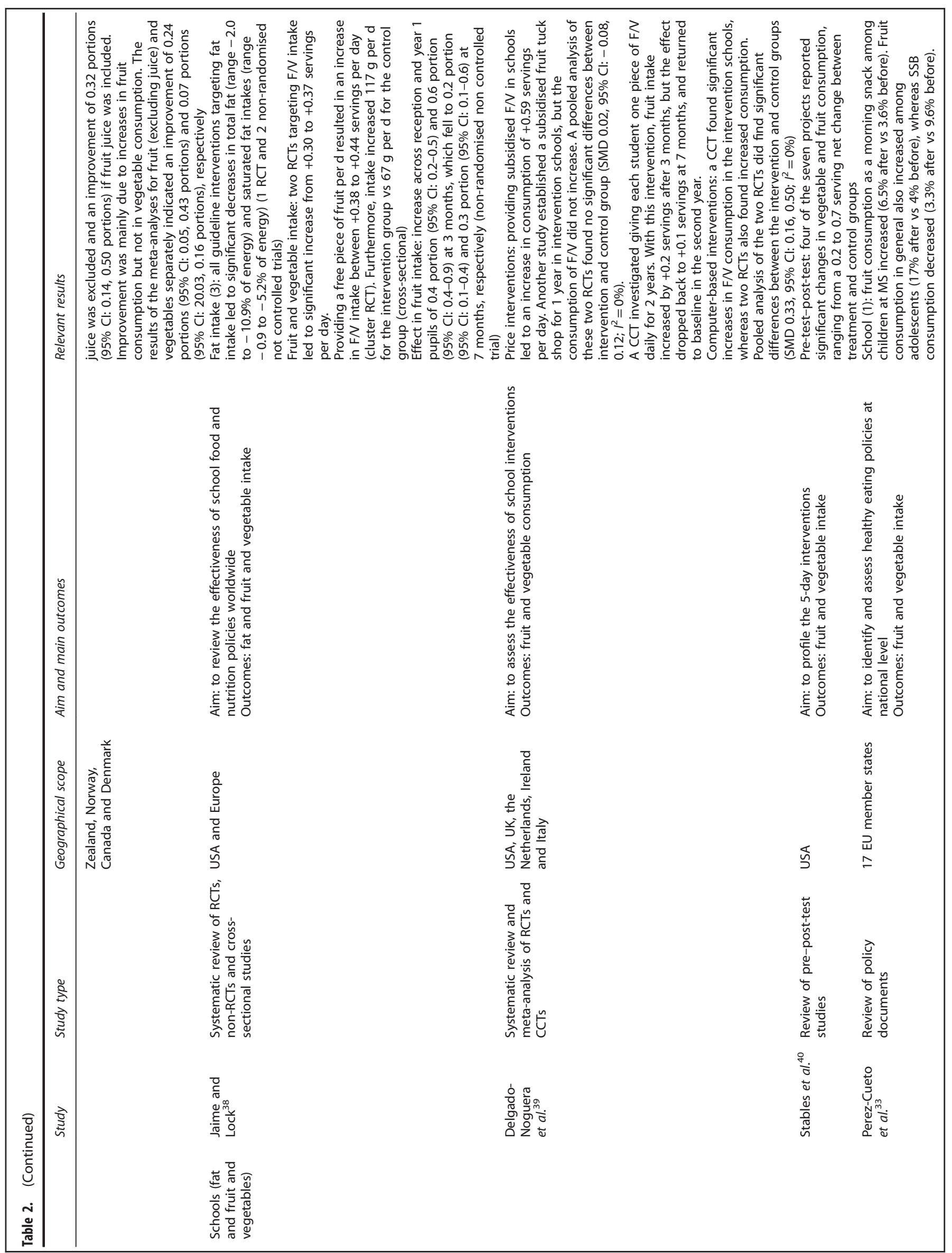




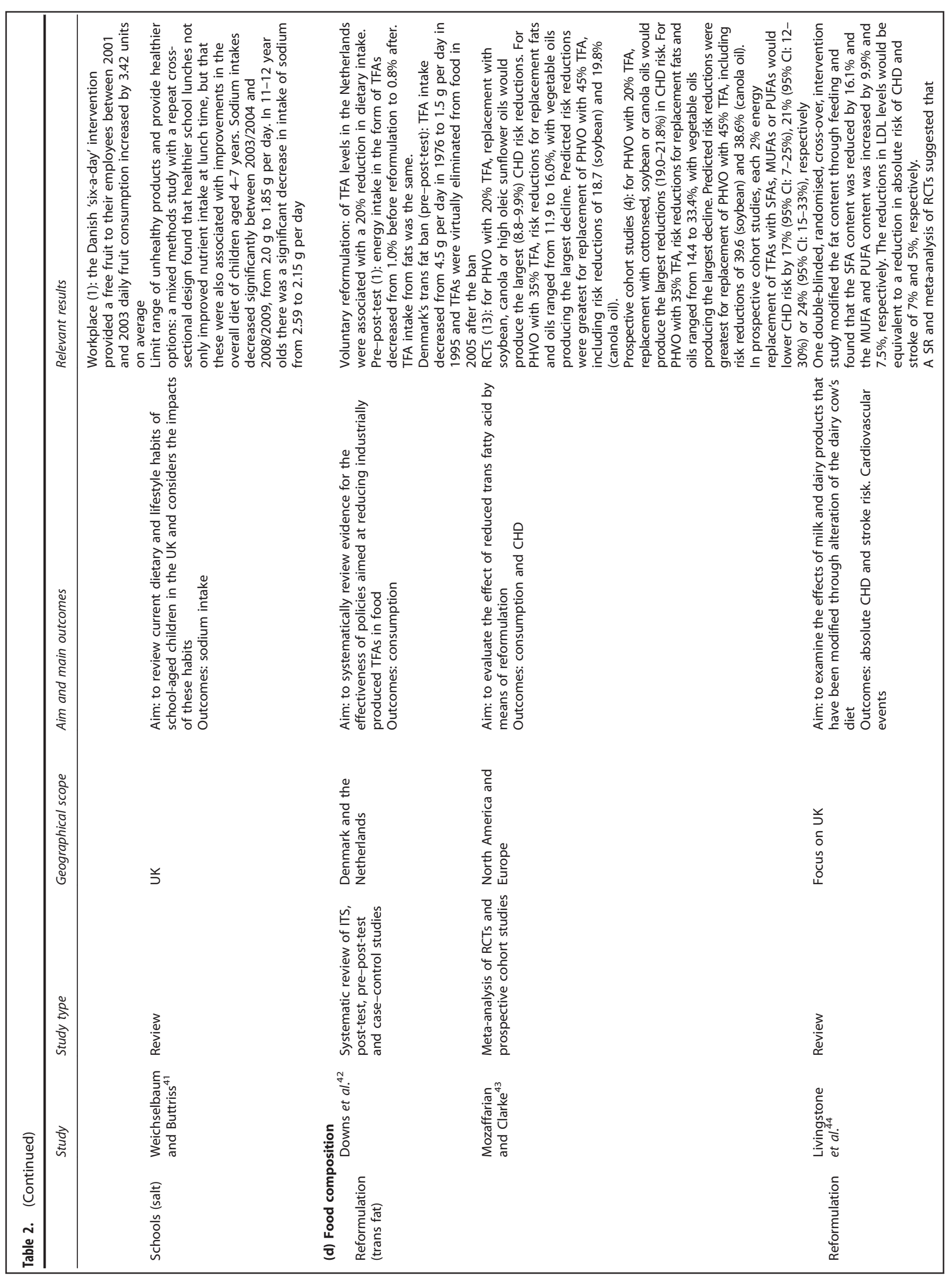




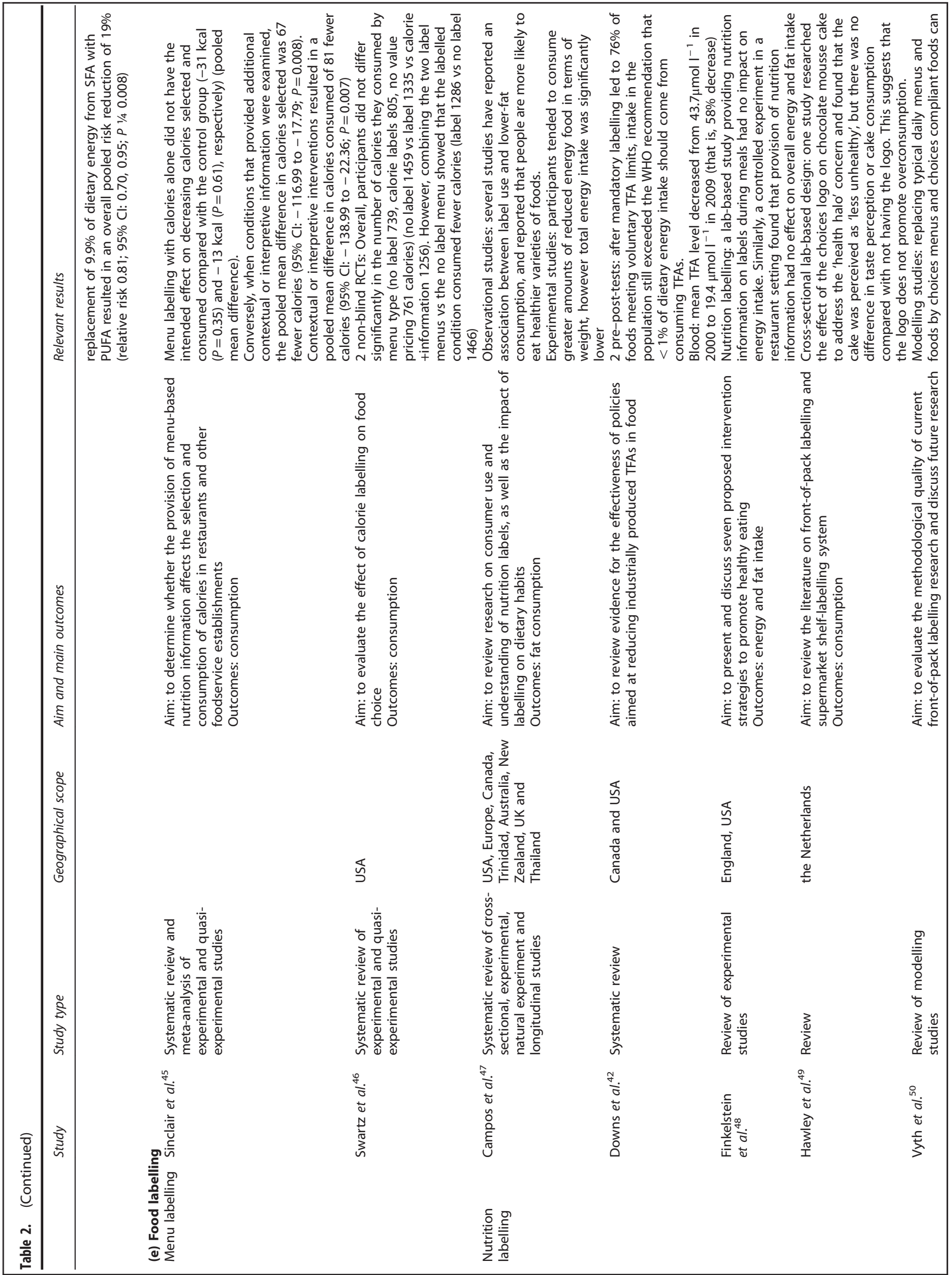




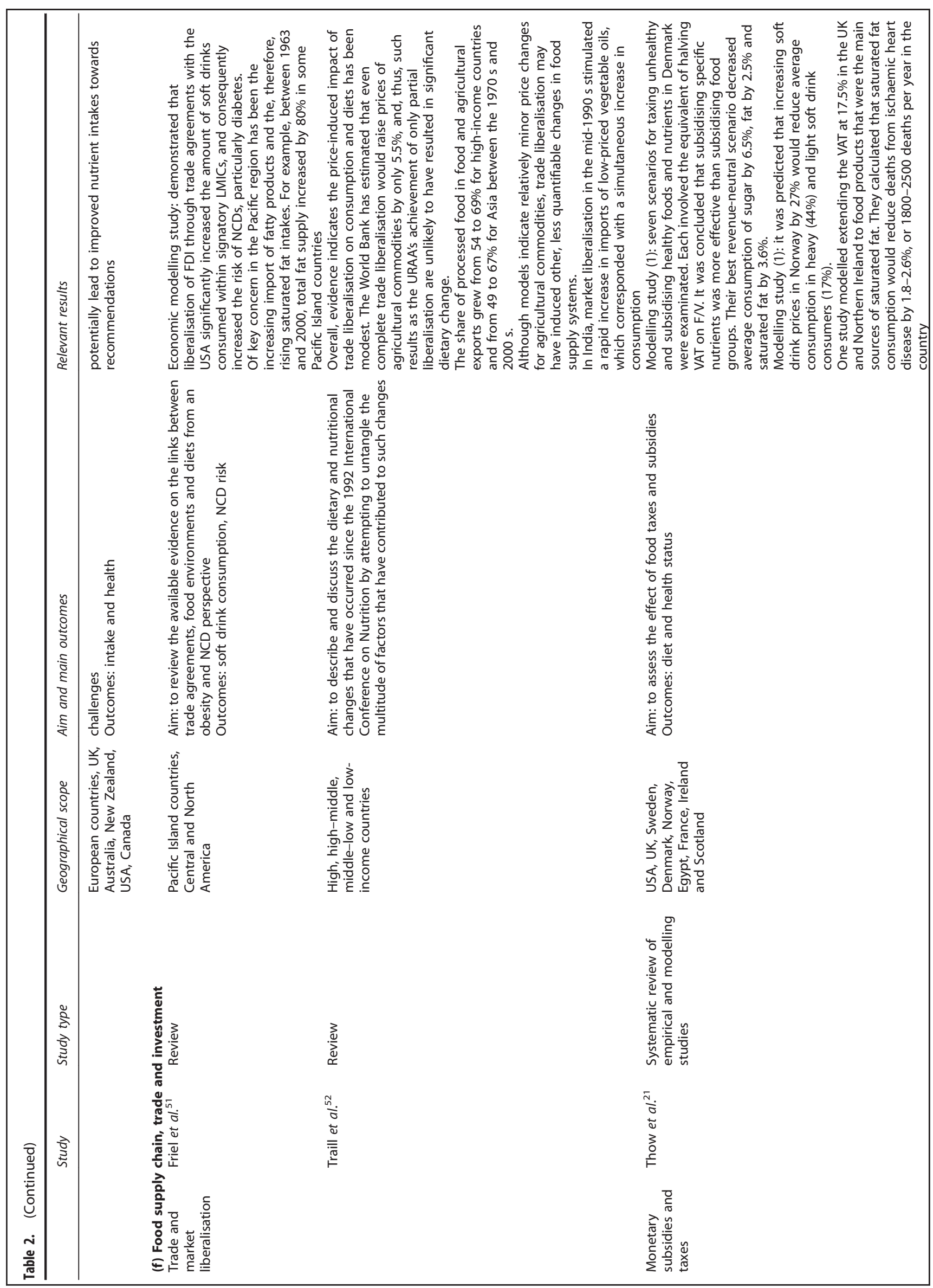




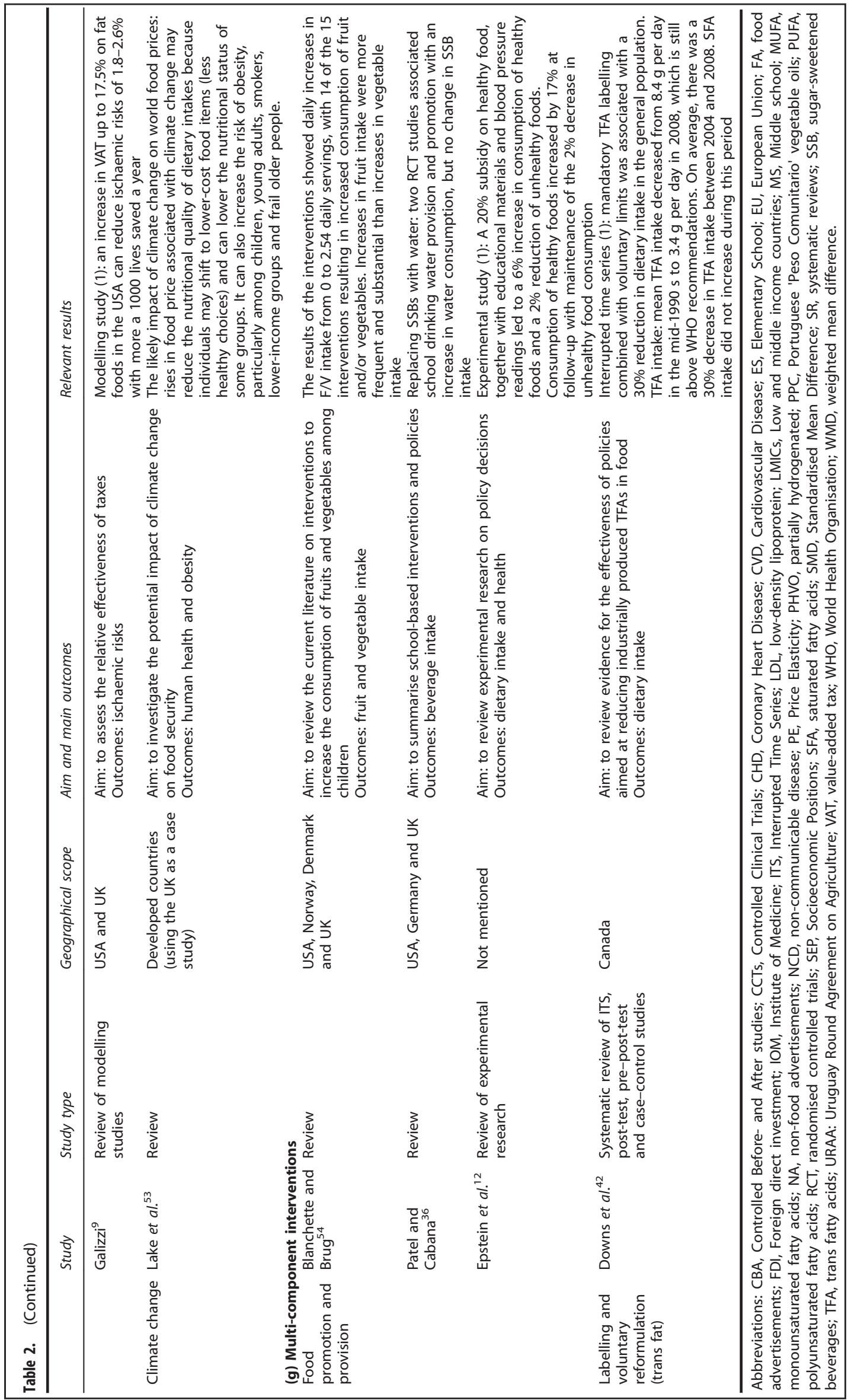


and are adapted from the 4P's marketing framework. Most interventions have subcategories, for example, food provision, which can be done in schools, communities or at workplaces. Within these categories the data were grouped according to the subcategories. Furthermore, as this review is about healthy eating, multiple nutrients are included. So another layer was added for these nutrients and the results were presented under their specific (sub-) categories for each of the nutrients. This structure was then used to present the results.

All the evidence for each sub-category was reviewed and analysed according to study design and the number of studies included investigating the same intervention and outcome. The key findings are presented in the results section and all the studies are then summarised in the tables.

As the study designs and evidence per nutrition varies greatly no quantitative comparison will be made between the interventions. They will each be presented separately.

\section{RESULTS}

About 1805 candidate publications were screened and 197 papers were retrieved for full-text screening. In all 139 were excluded as they had no quantitative outcomes or outcomes different to our inclusion criteria. We identified 58 systematic and non-SRs for inclusion (Figure 1). Eight reviews provided information on more than one category.

\section{Food price}

Taxes. One SR estimated a mean price (Table 2a) elasticity of -0.8 to -1.0 for sugar-sweetened beverages (SSBs). Thus, a $10 \%$ price increase is associated with an $8-10 \%$ reduction in SSB consumption. ${ }^{16}$ Furthermore, Thow et al. ${ }^{22}$ reported a $5-48 \%$ reduction in SSB consumption proportional to the modelled taxes applied (5-30\%).

However, taxing unhealthy food may cause substitution effects. For instance, a fat tax might reduce saturated fat content but increase salt content and product consumption. ${ }^{23}$ Four modelling studies included in Thow et al. $^{22}$ investigated these substitution effects. A 5-20\% SSB tax could reduce calorie intake of SSBs by $10-48 \%$ in adults and by $5-8 \%$ in children, however consumption of milk, tea, coffee and low-calorie beverages may increase correspondingly. ${ }^{22}$ Finally, Welsh et al. ${ }^{7}$ included a modelling study suggesting that a US penny-per-ounce tax might reduce SSB consumption by $15 \%$ among adults and subsequently prevent $\sim 95000$ coronary heart events, $\sim 8000$ strokes and $\sim 26000$ premature deaths.

Several reviews included at least one modelling study investigating a 'fat tax'. ${ }^{9,10,19,22}$ All suggested that changes in fat

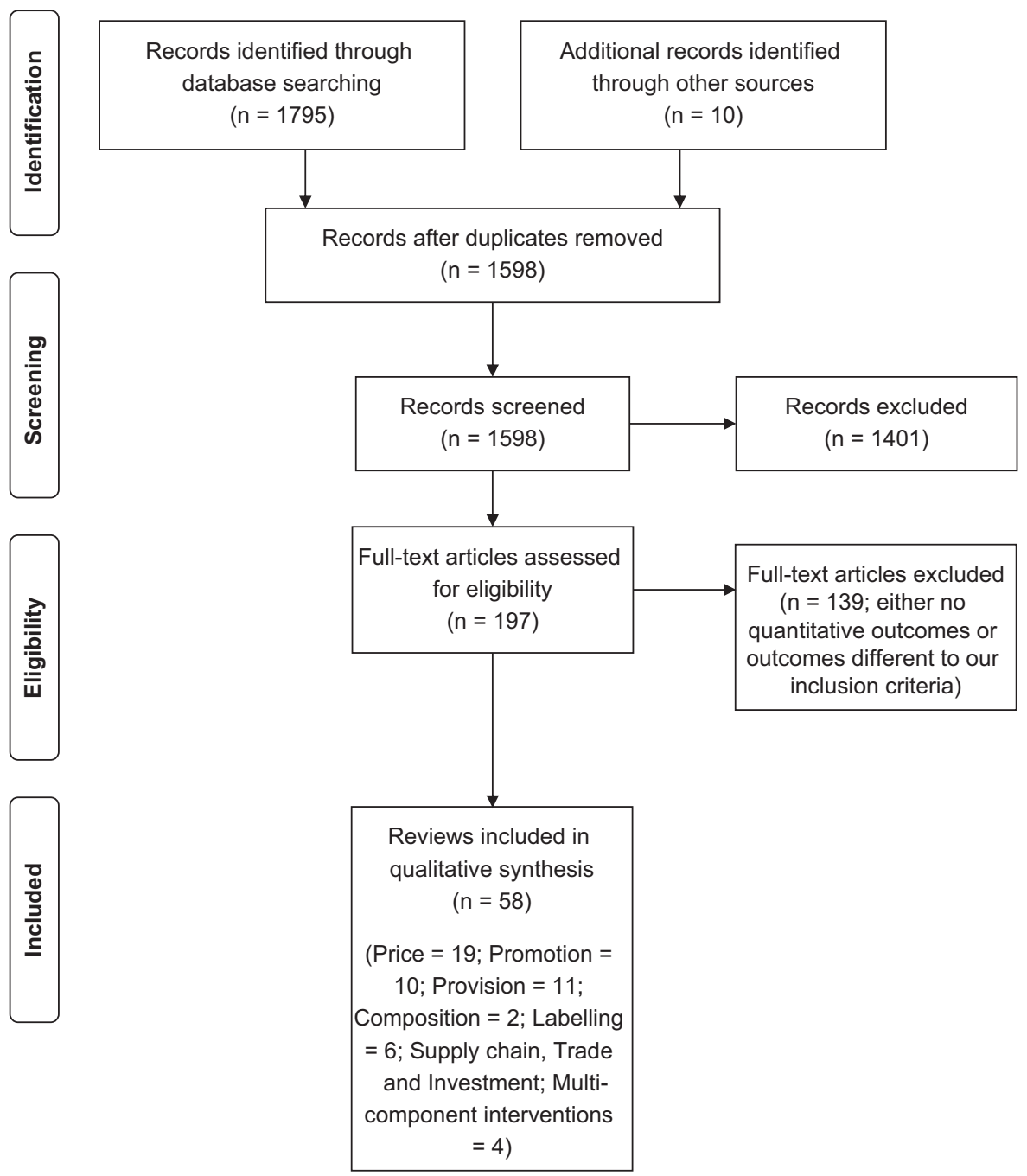

Figure 1. PRISMA flow diagram. 
consumption would be minor, unless the tax was substantial. Four modelling studies in Thow et al. $^{22}$ suggested that a small fat tax (5-17\%) might reduce (saturated) fat consumption by $0-3 \%$ and induced substitution with lower-fat options. Increasing the price of salty foods by $40 \%$ was suggested to reduce sodium consumption by $\sim 6 \% .^{22}$

Mozaffarian et $a .^{20}$ included a modelling study investigating a combination of taxing less healthy foods and using the $\$ 580$ million revenue raised to subsidise fruit and vegetables. This might alter consumption to prevent $\sim 6000$ CVD and cancer deaths annually.

Subsidies. Powell et al. included six modelling studies reporting -0.49 mean price elasticity for fruit and vegetables, suggesting a $20 \%$ subsidy on fruit and vegetables might increase consumption by $10 \%,{ }^{18}$ while a $10 \%$ subsidy might increase consumption by $5 \% .{ }^{22} \mathrm{~A}$ continuing price reduction on fruit and vegetables might prevent $\sim 6700$ cases of CHD and 2950 cases of ischaemic stroke. ${ }^{21}$

\section{Food promotion}

Marketing and advertising. Four randomised controlled trials (RCTs) in Gregori et al. ${ }^{25}$ (Table 2b) indicated that exposure to food advertisements compared with non-food advertisements increased calorie intake and snacks consumed. The effect appeared largest in obese children. Two cross-sectional studies by Boyland and Halford ${ }^{26}$ supported these findings. Conversely, banning food advertisements on television might reduce the US baseline rate of childhood obesity by $2.5-6.5 \%{ }^{27}$

Nutrition education. RCTs reviewed in two SRs suggested that nutrition education focused on fruit and vegetables could increase their intake by $0.4-1.4$ servings per day. ${ }^{28,30}$ Two additional RCTs reported a net increase of 0.4 servings per day. ${ }^{6}$

A meta-analysis of RCTs found that e-learning interventions focused on dietary intake increased fruit and vegetable intake by 0.24 servings per day; reduced total fat $(-0.8 \mathrm{~g})$, saturated fat $(-0.2 \mathrm{~g})$ and daily energy intake $(4 \mathrm{kcal}){ }^{29}$

Media campaigns. Three reviews focused on fruit and vegetables. ${ }^{31-33}$ Benefits were modest at best.

Food provision in schools, communities or workplaces

Schools. A cross-sectional and longitudinal study included in Levy et al. ${ }^{6}$ (Table 2c) investigated the effect of eliminating access to SSBs on consumption and found reductions of 0.16 servings per day and 4\%, respectively. Another time-series study found a $35 \%$ decline in consumption in schools after SSBs were removed from cafeteria vending machines. However, pupils obtained SSBs from home or non-cafeteria vending machines instead. ${ }^{6}$ A modelling study by Patel and Cabana ${ }^{36}$ suggested replacing SSBs with water might reduce intake by $235 \mathrm{kcal}$ per day among 2-19 year olds.

Jaime and Lock $^{38}$ reviewed the effect of a free piece of fruit in schools in three RCTs. Fruit and vegetable intake increased by $0.30-0.44$ servings per day. However, benefits were not necessarily sustained long term. ${ }^{38}$ Fat intake was targeted by one RCT and two non-randomised studies in the same review, reporting decreases in saturated fat $(0.9-5.2 \%$ of energy intake) and total fat $(2.0-10.9 \%){ }^{38}$ A meta-analysis of school interventions targeting fruit and vegetable intake found a higher effect when fruit juice was included ( 0.32 portions) compared with no fruit juice included (0.25 portions). ${ }^{37}$

Communities. No reviews were found for community interventions and the effect on dietary intake or health outcomes.
Workplaces. Thompson and $\mathrm{Ravia}^{30}$ reviewed RCTs of workbased interventions and reported 0.8 servings per day increase in fruit and vegetable intake. A meta-analysis of 36 RCTs also found a significant increase in daily fruit and vegetable consumption. ${ }^{35}$ Five RCTs in Mhurchu et al. ${ }^{34}$ focused on total fat intake as a percentage of energy and found reductions in both the intervention ( -2.2 to $-9.1 \%)$ and control groups (+1.3 to $-1.8 \%)$.

\section{Food composition}

Trans fats. Downs et al. ${ }^{42}$ included two pre-post-test studies evaluating (Table $2 \mathrm{~d}$ ) the effectiveness of interventions aimed to reduce trans fatty acids (TFAs) in food. In Denmark average iTFA intake decreased from $4.5 \mathrm{~g}$ per day in 1976 to $1.5 \mathrm{~g}$ per day in 1995 and reduced to virtually zero after the ban in $2005 .{ }^{34}$ In The Netherlands, voluntary reformulation of TFAs decreased daily energy intake from 1.0 to $0.8 \%$ (a $20 \%$ reduction). ${ }^{42}$

Mozaffarian and Clarke ${ }^{43}$ conducted two meta-analyses with 13 RCTs and 4 prospective studies to calculate the effect of reduced TFAs in partially hydrogenated vegetable oils by means of reformulation. The predicted risk reductions were greatest when replacing at least half of the iTFA in partially hydrogenated vegetable oils, with soybean oil or canola oil. ${ }^{43}$

\section{Food labelling}

Menu labelling. Two SRs evaluated the effect of menu labelling on dietary intake (Table 2e). Swartz et al. ${ }^{46}$ included two non-blind RCTs that reported no significant impact of menu labelling on calorie consumption. However, when combining the labels and labels/information categories vs no label, the labelled condition consumed 180 fewer calories. ${ }^{46}$ Similar results were found by a meta-analysis of 17 studies conducted by Sinclair et al. ${ }^{45}$

Nutrition labelling. Observational studies in Campos et al. ${ }^{47}$ reported an association between nutrition label use and fat consumption. Furthermore, experimental research included showed that participants tended to consume more energy reduced foods in terms of weight, but the overall energy intake was significantly lower. ${ }^{47}$ The theoretical concern that labelling might lead to overconsumption of foods perceived as 'less unhealthy' and appeared to be unfounded in a cross-sectional study by Hawley et al. $^{49}$

Food supply chain, trade and investment

Trade and market liberalisation. Evidence for the effect of trade (Table 2f) market liberalisation on dietary intake is contested. Traill suggested only 'modest' effects, ${ }^{52}$ whereas a study included in Friel et al. $^{51}$ argues that liberalisation of Foreign Direct Investment through trade agreements with the USA significantly increased soft drink consumption within low- and middle-income countries.

Monetary subsidies and taxes. Thow et al. ${ }^{21}$ included two modelling studies; one suggested that increasing value-added tax in the UK on the main sources of saturated fat might reduce consumption and thereby decrease CHD deaths by $1.8-2.6 \%$. The other suggested that halving value-added tax on fruit and vegetables could decrease consumption of sugar $(-6.5 \%)$, fat $(-2.5 \%)$ and saturated fat $(-3.6 \%)^{21}$

Reformulation. Livingstone et al. ${ }^{44}$ reviewed reformulation in the supply chain by altering the diet of cows and investigated the effect on milk and dairy products. A double-blinded randomised cross-over intervention study found a $16 \%$ decrease in saturated fats and increase in monounsaturated fats $(+10 \%)$ and polyunsaturated fats (+7.5\%). A meta-analysis of RCTs suggested that replacing $10 \%$ of dietary saturated fat intake with polyunsaturated fats might reduce $\mathrm{CHD}$ risk by $10 \% .{ }^{44}$ 
Multi-component interventions

Trans fats. Voluntary limits combined with mandatory labelling (Table $2 \mathrm{~g}$ ) were associated with a $30 \%$ reduction in dietary trans fat intake in the general population, in an interrupted time-series study in Downs et al. ${ }^{42}$

Fruit and vegetables. Fifteen intervention studies in Blanchette and Burg ${ }^{54}$ combined provision and promotion activities, and found an increase in fruit and vegetable intake of 2.54 servings per day. Conversely, single interventions rarely increased intake by more than 0.5 servings. ${ }^{38-40}$

Salt. No reviews have evaluated the effects of multi-component interventions on salt intake. However, the UK salt programme has been evaluated and a $1.5 \mathrm{~g}$ per day (15\%) reduction was observed between 2001 and 2011. This was achieved by sustained and progressive industry reformulation involving close monitoring and political pressure to ensure compliance, reinforced by media campaigns and traffic light food labelling. ${ }^{56,57}$

\section{DISCUSSION}

Main findings

Our rapid scoping review suggests that 'upstream' interventions such as price interventions appear to be consistently effective in improving healthy eating. ${ }^{9,16,18-21,25}$ Multi-component interventions and reformulation also appear effective in promoting healthy diets. However, the effectiveness of the remaining policy interventions (labelling, restrictions on the provision or marketing of unhealthy food) generally demonstrated smaller effects and less certain long-term benefits. ${ }^{29,36}$

\section{Specific findings}

Food price. Taxes and subsidies appear to be consistently effective at reducing consumption of sugary drinks, ${ }^{16,22}$ and increasing the consumption of fruit and vegetables. ${ }^{18,21,22}$ Changes in consumption demonstrated price elasticity, thus the larger the taxes or subsidies, the greater the effect. ${ }^{16,22} \mathrm{~A}$ fat tax, however, appeared to have smaller impacts on consumption, ${ }^{9,19,22}$ and potential substitution effects need to be anticipated and negated. $^{22,23}$

Food promotion. Junk food advertisements significantly increase total calorie intake. Banning advertising to children therefore appears to offer an effective intervention to decrease intake and potentially reduce obesity levels. ${ }^{25,26}$ Health promotion campaigns $^{31-33}$ and nutrition education ${ }^{6,28-30}$ showed small effect sizes and benefits may diminish over time. More studies are needed to determine long-term effects.

Food provision. Most school-based interventions focused on fruit and vegetables ${ }^{37,38}$ or access to SSBs. ${ }^{6,36}$ Overall, these interventions seemed to be effective in the short term but effect sizes are generally small and longer-term effects were not routinely investigated.

The majority of workplace interventions focused on fruit and vegetable intake, ${ }^{30,35}$ with a few focusing on fat intake, ${ }^{34}$ and effects were generally modest.

Food composition. Mandatory reformulation to eliminate trans fat was very effective in Denmark, reducing consumption far more than voluntary reformulation. This is in line with a modelling study comparing voluntary with mandatory salt reformulation policies. ${ }^{58}$ Furthermore, Cappuccio et al. ${ }^{59}$ suggested that nation-wide reformulation policies might reduce salt consumption by $1 \mathrm{~g}$ per day.
Food labelling. Although menu labelling appears weak or ineffective, food labelling may help consumers to choose and purchase healthier options, ${ }^{46}$ while also exerting pressure on manufacturers to reformulate. ${ }^{60}$ Furthermore, although $50 \%$ of EU consumers might use food labels; many report difficulties in interpreting the labels. ${ }^{47,61}$ However, the current evidence is based on diverse methodologies and remains limited. ${ }^{62}$

Food supply chain, trade and investment. Food supply chain interventions appear intuitively powerful, but are underresearched. Interventions could take place at many levels of the food supply chain, with positive (or negative) effects on food availability, price, quality or marketing. ${ }^{51-53}$ Targeted reformulation, subsidies and taxes in the food supply chain could have beneficial effects on diet-related health outcomes. ${ }^{44}$

Multi-component interventions. Multi-component interventions appear to be highly effective at reducing the dietary intake of salt, industrial trans fats and increasing fruit and vegetable consumption, thus improving health outcomes at population level. ${ }^{56,57}$ However, salt intake remains very high in most countries; often double the World Health Organisation recommended maximum levels of $5 \mathrm{~g}$ per day. ${ }^{63}$

Likewise, industrial trans fat levels have been slashed in Denmark, the USA and parts of Western Europe but remain high elsewhere. ${ }^{42}$ Furthermore, the reviews included only considered trans fat and fruit and vegetable intake. It is, therefore, not clear whether multi-component interventions might be equally effective for other dietary components such as sugar and total fat.

\section{Strengths of this analysis}

This scoping review used two independent researchers to screen all the papers generated through the searches. Discrepancies were resolved through consensus or consulting a third senior researcher. Furthermore, a systematic approach was used based on the seven-item interventions framework.

Food supply chain, trade and investment is an underexplored area; however there is some evidence to suggest that globalisation and liberalisation of markets can influence dietary patterns and NCDs. Multi-component interventions are as suggested effective to reduce dietary intake and NCDs. Countries have implemented several policies at the same time and it is important to quantify the impact compared with single policies.

\section{Limitations of this analysis}

This scoping review has several limitations. First, we only searched for reviews from the last 10 years. However, we anticipate this captured majority of relevant reviews and thus provide an excellent overview of current food policy interventions. Second, only reviews with an abstract available in English were included. Third, this scoping review focussed on systematic and non-SRs only, thereby missing areas lacking such reviews. However, we explicitly included both systematic and non-SRs to explore underresearched areas. Fourth, some effect measures were too unclear to include in the tables because it was not possible to go back to individual studies. Furthermore, as our inclusion criteria were only focused on dietary intake (consumption) and health outcomes; studies considering any other precursors to dietary behaviour such as purchasing behaviour, awareness, knowledge, preferences and availability were not presented. Also, most studies included were conducted in high-income or middle-income countries; generalisation of the results to low-income settings might be problematic. Fifth, whereas the effects of price interventions can be quantified and occurred immediately, nutrition education and health promotion campaigns have long-term effects that cannot be so easily measured. Finally, systematic and non-SRs included many different study methodologies. Outputs from RCTs, 
observational cohorts, natural experiments and modelling studies are all potentially valid, but may not be directly comparable and should therefore be interpreted with caution. We have, therefore, routinely presented such results separately.

\section{Future research}

The logical next step is to conduct a fully resourced SR that includes all relevant primary studies. This could explore whether effectiveness varies in different ethnic or socioeconomic subgroups, as socioeconomic deprivation is often associated with increased intake of foods high in saturated fat and sugar, poor nutrition and poorer health. Downstream interventions (such as advice to individuals) may widen the inequalities gap, whereas population-based policy interventions may reduce inequalities. Finally, the few analyses of multi-component interventions suggest that they may be more effective than single interventions. Further research is needed in all these areas.

\section{CONCLUSIONS}

Diverse policy interventions exist to improve healthy eating and thus prevent NCD. The evidence base varies for each category and nutrient. The evidence base for price interventions appears to be comprehensive and included studies mostly on taxing SSBs, followed by taxing dietary fat. Studies investigating the effect of subsidies mainly focused on fruit and vegetable intake. Taxes consistently decrease SSB consumption, whereas subsidies increase fruit and vegetable intake. Only a few reviews were included for food composition. The Denmark trans fat story suggests that voluntary reformulation can be effective to start with; however, a legislative ban is able to then essentially eliminate industrial trans fat consumption. Mandatory reformulation is thus consistently more effective than voluntary reformulation. Health promotion campaigns and nutrition education benefits appear modest and effects usually reduce over time. Limiting the marketing of junk food and sugary drinks appears to be effective and, thus, a ripe target for regulation.

Workplace interventions appeared to be modestly effective at increasing fruit and vegetable intake. School interventions showed a modest effect of reducing SSB consumption and increase fruit and vegetable consumption in schools. The effects for food labelling were mixed. Labelling may help pressure reformulation by manufacturers and inform consumer choice. However, much depends on individual awareness, knowledge and ability to interpret labels correctly. Trade and investment factors controlling the food supply chain may be powerful but are currently underresearched. Finally, multi-component interventions appear to be more effective than single interventions. This might be predicted, having previously been reported in tobacco control, where comprehensive, coordinated programs are superior to single interventions. $^{64}$

\section{CONFLICT OF INTEREST}

The authors declare no conflict of interest.

\section{ACKNOWLEDGEMENTS}

LH was supported by funding from WHO European Region Office. Other author's salaries came mainly from the Higher Education Funding Council for England (HEFCE), with none from industry or Pharma.

\section{REFERENCES}

1 Lozano R, Naghavi M, Foreman K, Lim S, Shibuya K, Aboyans V et al. Global and regional mortality from 235 causes of death for 20 age groups in 1990 and 2010: a systematic analysis for the Global Burden of Disease Study 2010. Lancet 2012; 380: 2095-2128.
2 WHO. Global Burden of Metabolic Risk Factors for Chronic Diseases Collaboration. Risk factor estimates for 2004. Cardiovascular disease, chronic kidney disease, and diabetes mortality burden of cardiometabolic risk factors from 1980 to 2010: a comparative risk assessment. Lancet Diabetes Endocrinol 2014; 2: 634-647.

3 Brownson RC, Seiler R, Eyler AA. Measuring the impact of public health policy. Prev Chronic Dis 2010; 7: A77.

4 Grier S, Bryant CA. Social marketing in public health. Annu Rev Public Health 2005; 26: 319-339.

5 Cabrera Escobar MA, Veerman JL, Tollman SM, Bertram MY, Hofman KJ. Evidence that a tax on sugar sweetened beverages reduces the obesity rate: a meta-analysis. BMC Public Health 2013; 13: 1072.

6 Levy DT, Friend KB, Wang YC. A review of the literature on policies directed at the youth consumption of sugar sweetened beverages. Adv Nutr 2011; 2: 182S-200S.

7 Welsh JA, Lundeen EA, Stein AD. The sugar-sweetened beverage wars: public health and the role of the beverage industry. Curr Opin Endocrinol Diabetes Obes 2013; 20: 401-406.

8 Cash SB, Lacanilao RD. Taxing food to improve health: economic evidence and arguments. Agr Resour Econ Rev 2007; 36: 174-182.

9 Galizzi MM. Label, nudge or tax? A review of health policies for risky behaviours. J Public Health Res 2012; 1: 14-21.

10 Tiffin R, Salois M. Inequalities in diet and nutrition. Proc Nutr Soc 2012; 71: 105-111.

11 Faulkner GEJ, Grootendorst P, Nguyen VH, Andreyeva T, Arbour-Nicitopoulos K, Auld $\mathrm{MC}$ et al. Economic instruments for obesity prevention: results of a scoping review and modified Delphi survey. Int J Behav Nutr Phys Act 2011; 8: 109 .

12 Epstein LH, Jankowiak N, Nederkoorn C, Raynor HA, French SA, Finkelstein E. Experimental research on the relation between food price changes and foodpurchasing patterns: a targeted review. Am J Clin Nutr 2012; 95: 789-809.

13 Powell LM, Chaloupka FJ. Food prices and obesity: evidence and policy implications for taxes and subsidies. Milbank Q 2009; 87: 229-257.

14 Black AP, Brimblecombe J, Eyles H, Morris P, Vally H, Dea OK. Food subsidy programs and the health and nutritional status of disadvantaged families in high income countries: a systematic review. BMC Public Health 2012; 12: 1099.

15 An R. Effectiveness of subsidies in promoting healthy food purchases and consumption: a review of field experiments. Public Health Nutr 2013; 16: 1215-1228.

16 Andreyeva T, Long MW, Brownell KD. The impact of food prices on consumption: a systematic review of research on the price elasticity of demand for food. Am J Public Health 2010; 100: 216-222.

17 Maniadakis N, Kapaki V, Damianidi L, Kourlaba G. A systematic review of the effectiveness of taxes on nonalcoholic beverages and high-in-fat foods as a means to prevent obesity trends. Clinicoecon Outcomes Res 2013; 5: 519-543.

18 Powell LM, Chriqui JF, Khan T, Wada R, Chaloupka FJ. Assessing the potential effectiveness of food and beverage taxes and subsidies for improving public health: a systematic review of prices, demand and body weight outcomes. Obes Rev 2013; 14: 110-128.

19 Eyles $\mathrm{H}, \mathrm{Ni}$ Mhurchu C, Nghiem N, Blakely T. Food pricing strategies, population diets, and non-communicable disease: a systematic review of simulation studies. PLoS Med 2012; 9: e1001353.

20 Mozaffarian D, Afshin A, Benowitz NL, Bittner V, Daniels SR, Franch HA et al. Population approaches to improve diet, physical activity, and smoking habits: a scientific statement from the American Heart Association. Circulation 2012; 126: 1514-1563.

21 Thow AM, Jan S, Leeder S, Swinburn B. The effect of fiscal policy on diet, obesity and chronic disease: a systematic review. Bull World Health Organ 2010; 88: 609-614.

22 Thow AM, Downs S, Jan S. A systematic review of the effectiveness of food taxes and subsidies to improve diets: understanding the recent evidence. Nutr Rev 2014; 72: 551-565.

23 Capacci S, Mazzocchi M, Shankar B, Macias JB, Verbeke W, Pérez-Cueto FJ et al. Policies to promote healthy eating in Europe: a structured review of policies and their effectiveness. Nutr Rev 2012; 70: 188-200.

24 Schultz DJ, Byker Shanks C, Houghtaling B. The impact of the 2009 Special Supplemental Nutrition Program for women, infants, and children food package revisions on participants: a systematic review. J Acad Nutr Diet 2015; 115: 1832-1846.

25 Gregori D, Ballali S, Vecchio MG, Sciré AS, Foltran F, Berchialla P. Randomized controlled trials evaluating effect of television advertising on food intake in children: why such a sensitive topic is lacking top-level evidence? Ecol Food Nutr 2014; 53: 562-577.

26 Boyland EJ, Halford JCG. Television advertising and branding. Effects on eating behaviour and food preferences in children. Appetite 2013; 62: 236-241. 
27 Hingle M, Kunkel D. Childhood obesity and the media. Pediatr Clin North Am 2012; 59: 677-692.

28 Mytton OT, Nnoaham K, Eyles H, Scarborough P, Ni Mhurchu C. Systematic review and meta-analysis of the effect of increased vegetable and fruit consumption on body weight and energy intake. BMC Public Health 2014; 14: 886.

29 Harris J, Felix L, Miners A, Murray E, Michie S, Ferguson E et al. Adaptive e-learning to improve dietary behaviour: a systematic review and cost-effectiveness analysis. Health Technol Assess 2011; 15: 1-160.

30 Thomson CA, Ravia J. A systematic review of behavioral interventions to promote intake of fruit and vegetables. J Am Diet Assoc 2011; 111: 1523-1535.

31 Rekhy R, McConchie R. Promoting consumption of fruit and vegetables for better health. Have campaigns delivered on the goals? Appetite 2014; 79: 113-123.

32 Snyder LB. Health communication campaigns and their impact on behavior. J Nutr Educ Behav 2007; 39(2 Suppl): S32-S40.

33 Pérez-Cueto FJA, Aschemann-Witzel J, Shankar B, Brambila-Macias J, Bech-Larsen T, Mazzocchi $M$ et al. Assessment of evaluations made to healthy eating policies in Europe: a review within the EATWELL Project. Public Health Nutr 2012; 15: 1489-1496.

$34 \mathrm{Ni}$ Mhurchu C, Aston LM, Jebb SA. Effects of worksite health promotion interventions on employee diets: a systematic review. BMC Public Health 2010; 10: 62.

35 Montano D, Hoven $\mathrm{H}$, Siegrist J. A meta-analysis of health effects of randomized controlled worksite interventions: does social stratification matter? Scand J Work Environ Health 2014; 40: 230-234.

36 Patel Al, Cabana MD. Encouraging healthy beverage intake in child care and school settings. Curr Opin Pediatr 2010; 22: 779-784.

37 Evans CE, Christian MS, Cleghorn CL, Greenwood DC, Cade JE. Systematic review and meta-analysis of school-based interventions to improve daily fruit and vegetable intake in children aged 5 to 12 y. Am J Clin Nutr 2012; 96: 889-901.

38 Jaime PC, Lock K. Do school based food and nutrition policies improve diet and reduce obesity? Prev Med 2009; 48: 45-53.

39 Delgado-Noguera M, Tort S, Martínez-Zapata MJ, Bonfill X. Primary school interventions to promote fruit and vegetable consumption: a systematic review and meta-analysis. Prev Med 2011; 53: 3-9.

40 Stables GJ, Young EM, Howerton MW, Yaroch AL, Kuester S, Solera MK et al. Small school-based effectiveness trials increase vegetable and fruit consumption among youth. J Am Diet Assoc 2005; 105: 252-256.

41 Weichselbaum E, Diet Buttriss JL. Nutrition and schoolchildren: an update. Nutr Bull 2014; 39: 9-73.

42 Downs SM, Thow AM, Leeder SR. The effectiveness of policies for reducing dietary trans-fat: a systematic review of the evidence. Bull World Health Organ 2013; 91: 262-9H.

43 Mozaffarian D, Clarke R. Quantitative effects on cardiovascular risk factors and coronary heart disease risk of replacing partially hydrogenated vegetable oils with other fats and oils. Eur J Clin Nutr 2009; 63(Suppl 2): S22-S33.

44 Livingstone KM, Lovegrove JA, Givens DI. The impact of substituting SFA in dairy products with MUFA or PUFA on CVD risk: evidence from human intervention studies. Nutr Res Rev 2012; 25: 193-206.

45 Sinclair SE, Cooper M, Mansfield ED. The influence of menu labelling on calories selected or consumed: a systematic review and meta-analysis. J Acad Nutr Diet 2014; 114: 1375-88.e15.

46 Swartz JJ, Braxton D, Viera AJ. Calorie menu labeling on quick-service restaurant menus: an updated systematic review of the literature. Int J Behav Nutr Phys Act 2011; 8: 135.
47 Campos S, Doxey J, Hammond D. Nutrition labels on pre-packaged foods: a systematic review. Public Health Nutr 2011; 14: 1496-1506.

48 Finkelstein E, French S, Variyam JN, Haines PS. Pros and cons of proposed interventions to promote healthy eating. Am J Prev Med 2004; 27(3 Suppl.): 163-171.

49 Hawley KL, Roberto CA, Bragg MA, Liu PJ, Schwartz MB, Brownell KD. The science on front-of-package food labels. Public Health Nutr 2013; 16: 430-439.

50 Vyth EL, Steenhuis IHM, Brandt HE, Roodenburg AJC, Brug J, Seidell JC. Methodological quality of front-of-pack labeling studies: a review plus identification of research challenges. Nutr Rev 2012; 70: 709-720.

51 Friel S, Hattersley L, Snowdon W, Hallam D. Monitoring the impacts of trade agreements on food environments. Obes Rev 2013; 14(Suppl 1): 120-134.

52 Traill WB, Mazzocchi M, Shankar B, Hallam D. Importance of government policies and other influences in transforming global diets. Nutr Rev 2014; 72: 591-604.

53 Lake IR, Hooper L, Abdelhamid A, Bentham G, Boxall AB, Draper A et al. Climate change and food security: health impacts in developed countries. Environ Health Perspect 2012; 120: 1520-1526.

54 Blanchette L, Brug J. Determinants of fruit and vegetable consumption among 612-year-old children and effective interventions to increase consumption. J Hum Nutr Diet 2005; 18: 431-443.

55 Centre for Reviews and Dissemination Systematic Reviews: CRD's Guidance for Undertaking Reviews in Health Care. University of York: York, UK: 2009.

$56 \mathrm{He}$ FJ, Jenner KH, Macgregor GA. WASH-world action on salt and health. Kidney Int 2010; 78: 745-753.

57 He FJ, Brinsden HC, Macgregor GA. Salt reduction in the United Kingdom: a successful experiment in public health. J Hum Hypertens 2014; 28: 345-352.

58 Collins M, Mason H, O'Flaherty M, Guzman-Castillo M, Critchley J, Capewell S. An economic evaluation of salt reduction policies to reduce coronary heart disease in England: a policy modeling study. Value Health 2014; 17: 517-524.

59 Cappuccio FP, Capewell S, Lincoln P, McPherson K. Policy options to reduce population salt intake. BMJ 2011; 343: d4995.

60 Unnevehr LJ, Jagmanaite E. Getting rid of trans fats in the US diet: policies, incentives and progress. Food Policy 2008; 33: 497-503.

61 Cowburn G, Stockley L. Consumer understanding and use of nutrition labelling: a systematic review. Public Health Nutr 2005; 8: 21-28.

62 NICE Public Health Guidance. Prevention of Cardiovascular Disease at Population Level. 2010. Available at: http://guidance.nice.org.uk/PH25.

63 WHO. Guideline: Sodium Intake for Adults and Children. World Health Organization: Geneva 2012.

64 Green LW, Kreuter MW. Evidence hierarchies versus synergistic interventions. Am J Public H 2010; 100: 1824-1825.

(c) This work is licensed under a Creative Commons Attribution 4.0 cc) International License. The images or other third party material in this article are included in the article's Creative Commons license, unless indicated otherwise in the credit line; if the material is not included under the Creative Commons license, users will need to obtain permission from the license holder to reproduce the material. To view a copy of this license, visit http://creativecommons.org/licenses/ by/4.0/

(c) The Author(s) 2017

Supplementary Information accompanies this paper on European Journal of Clinical Nutrition website (http://www.nature.com/ejcn) 